\title{
Chapter 16 \\ Changes in the Use of Green Spaces by Citizens Before and During the First COVID-19 Pandemic: A Big Data Analysis Using Mobile-Tracking GPS Data in Kanazawa, Japan
}

\author{
Yusuke Ueno, Sadahisa Kato, Tomoka Mase, Yoji Funamoto, \\ and Keiichi Hasegawa
}

\begin{abstract}
To consider green spaces and parks as valuable green infrastructure that provides various socio-ecological benefits, including health, this study analyzed changes in the use of green spaces before and during the first COVID-19 pandemic in Japan, using mobile-tracking GPS data of Kanazawa citizens. The results showed that the declaration of a state of emergency in April-May 2020 changed the outing behavior of Kanazawa citizens, and there was a strong tendency for them to avoid going out, with a decrease in the number, time, and distance of outings. On the other hand, while citizens refrained from going out, the rate of decrease in the number of visits to green spaces was smaller compared to commercial areas, and the number of walks increased slightly from 2019. The distance traveled to green spaces is generally shorter in 2020, and the number of visits to green spaces near one's home increased in 2020. These findings suggest that those who had green spaces around their homes were able to use them for maintaining their health and refreshment during the COVID-19 pandemic, adding to the increasing evidence for the value of urban green spaces as part of nature-based solutions.
\end{abstract}

\footnotetext{
Y. Ueno $(\bowtie) \cdot$ T. Mase

Faculty of Bioresources and Environmental Sciences, Ishikawa Prefectural University, Nonoichi, Ishikawa, Japan

e-mail: uenoyu@ishikawa-pu.ac.jp

S. Kato

Faculty of Environmental Studies, Tottori University of Environmental Studies, Tottori, Tottori, Japan

Y. Funamoto

Fukuyama Consultants Co., Ltd./Social Value Incubation Lab., Tokyo, Japan

K. Hasegawa

EY Strategy and Consulting Co., Ltd., Tokyo, Japan
}

(C) The Author(s) 2022

F. Nakamura (ed.), Green Infrastructure and Climate Change Adaptation, Ecological Research Monographs, https://doi.org/10.1007/978-981-16-6791-6_16 
Keywords Behavioral change - COVID-19 - Green space · Public health · GPS data

\subsection{Introduction}

It is known that green spaces, essential element of green infrastructure, have functions such as improving people's health and providing recreational spaces. Previous studies reported that access and exposure to urban green spaces improves aspects of mental, physical, and social health of people (Zhou and Parves Rana 2012; Hartig et al. 2014; Fong et al. 2018; Kondo et al. 2018; Keeler et al. 2019; Bratman et al. 2019). For example, the statistical results from a Danish survey indicate that access to a garden or short distance to green areas from the dwelling is associated with less stress and a lower likelihood of obesity (Nielsen and Hansen 2007). These studies show that health is supported by a variety of mechanisms, including physical exercise, stress reduction, and social connections (Soga et al. 2021).

The COVID-19 pandemic triggered social reactions such as changes in people's behaviors including contact with nature. Lifestyle restrictions were forcefully set in place in response to the rapid spread of COVID-19 in early 2020. In many countries and cities, particularly in Europe and the USA, strict movement restrictions (e.g., stay-at-home order and restrictions on commuting and traveling) were placed, and the cities were "locked-down."

However, Japan's declaration of a state of emergency is different from the harsh measures taken by other countries. The prime minister at the time, Mr. Abe, declared a state of emergency in seven prefectures including Tokyo, Osaka, and Fukuoka on April 7, 2020, and expanded the scope of the state of emergency to the entire country on April 16 (NHK n.d.). In an emergency declaration, the prefectural governor can request residents to refrain from going out unnecessarily for a specified period and area, and request businesses to limit the hours of operation of their stores and facilities. This is different from other countries where cities are sealed off and severe penalties are imposed if the citizens do not comply. The restrictions on people's behavior under the emergency restrictions in Japan were voluntary (requested by the government), not mandatory, and there were no penalties and fines (NHK n.d.; NIKKEI 2020). Nevertheless, many people and businesses in Japan complied.

Regarding people's behaviors and the use of green spaces during the lockdown, there are recent research that showed how people's behaviors changed as to the use of green spaces before and during lockdown. For example, using STRAVA mobile application data, Venter et al. (2020) found a $291 \%$ increase in outdoor recreational activity over Oslo municipality, Norway, during March 2020 lockdown dates relative to the 3-yr baseline average. Both pedestrians (walking, running, hiking) and cyclists intensified activity on trails with greater greenery and in more remote areas. Pedestrian activity increased in city parks, peri-urban forest, as well as protected areas, highlighting the importance of access to green open 
spaces that are interwoven within the built-up matrix (Venter et al. 2020). Lu et al. (2020), by analyzing geotagged Instagram data of four Asian megacities (Hong Kong, Singapore, Tokyo, and Seoul), found that people were 5.3\% more likely to use green spaces for every 100 additional weekly new infection cases during the COVID-19 pandemic in March 2020. They also showed that people preferred larger, nature parks that are close to city centers. Conducting an online survey, Lesser and Nienhuis (2020) found that activity restrictions during the COVID19 pandemic differentially affected Canadians who were active and inactive, and that physical activity was strongly associated with well-being outcomes in inactive individuals. They also reported for active and inactive participants, those classified as "flourishing" indicated greater nature relatedness than those who scored lower on the mental health continuum. In sum, the three literature shows that during the lockdown those people who actively sought access to and used green spaces received health benefits.

Given the increasing evidence of overall health benefits of green spaces and based on the above literature review, the research hypothesis was that those who had green spaces around their homes under the declared state of emergency used them to maintain their health and refresh themselves, while those who did not have green spaces around their homes stayed at home without access to them. To consider greenery as an infrastructure that meets citizens' needs and solves societal challenges (i.e., green infrastructure), this study analyzed changes in the use of green spaces before and during the first COVID-19 pandemic in Japan, using mobiletracking GPS data of Kanazawa citizens.

\subsection{Materials and Methods}

\subsubsection{Study Area}

The study area, Kanazawa City in Ishikawa Prefecture, is a region facing the Sea of Japan, with a total area of $468.79 \mathrm{~km}^{2}$ and an estimated population of 463,387 (as of April 1, 2019). The urban area is surrounded by mountains, rivers, and the sea, and there are many green spaces in the city. There are 574 urban parks in Kanazawa City, with a total area of 308.20 ha (as of April 1, 2016) (Kanazawa City n.d.).

The first case of the COVID-19 infection was confirmed in Ishikawa Prefecture on February 21, 2020 (Ishikawa Prefecture 2020). Subsequently, as a measure to prevent the spread of the infection, all prefectural schools were temporarily closed, prefectural events were postponed or cancelled, prefectural facilities were closed, and residents were asked to refrain from going out unnecessarily and to refrain from traveling to and from other prefectures. On April 13, the prefecture issued its own emergency declaration, and on April 16, it was placed by the Japanese government as one of the "designated prefectures on alert," which means that the prefecture needs to take special measures to prevent the spread of COVID-19, and 
the residents of the prefecture were asked to refrain from going out. The alert in Ishikawa continued until May 14.

\subsubsection{The GPS Data and Sample}

The GPS data used in the analysis was the location data of cell phone terminals (mobile GPS data) collected by Blogwatcher, Inc. (location data service provider for smartphones) with the consent of the individual. It does not contain any personally identifiable information but is a combination of the latitude and longitude recorded by the GPS (with an error accuracy of about 50 to $100 \mathrm{~m}$ ), the time recorded (every 5 minutes to several hours), and random alphanumeric characters used to identify the device.

The period covered by the data is 15 days each from May 1 to 15, 2019, and May 1 to 15,2020 . In Japan, there is a weeklong holiday in early May every year, and many people tend to enjoy leisure and travel during this period. Therefore, from the data collected during these periods, we extracted those records that continuously stayed in Kanazawa City at night as Kanazawa citizens. Furthermore, to enable comparison between 2019 and 2020, and to reduce the effect of variations in GPS data acquisition time between mobile devices, only devices with 2 years of records and data acquisition time of more than 20 hours per day were selected for analysis. As a result, the total number of data (terminals) used in this study was 13,710 for 2 years, and the total number of GPS logs was 3,542,408. Of these, 5482 terminals were able to record data in both 2019 and 2020, which is equivalent to about $1.18 \%$ of Kanazawa citizens. This study was approved by the Research Ethics Committee of Ishikawa Prefectural University, where the first author belongs, before being conducted.

\subsubsection{Analysis Methods}

\subsubsection{Behavioral Changes of Kanazawa Citizens}

To analyze changes in the behavior of Kanazawa citizens as a whole before and during the COVID-19 pandemic, comparisons were made between 2019 and 2020 with regard to the number of outings per day, time spent outside the home, distance outside the home (straight-line distance from the home), means of transportation, and types (large green areas, commercial areas) and locations of outings. The location of the home was presumed to be in the vicinity of the place where they mainly stay in the middle of the night. The means of transportation was determined based on the movement speed between GPS logs.

The number of outings was calculated based on the number of times people went out per day (the number of times they stayed outside their homes), and the time 
spent out was calculated based on the sum of the time spent outside their homes plus the time spent traveling (end of day - start of day - time spent at home). To determine whether a person was "staying" or not, data observed within a range of 100 m continuously for more than 5 minutes were judged to be "staying," and the coordinates of the center of gravity within that time were considered to be "staying position." As for the means of transportation, the number of outings by means (walk, walking; cycle, bicycling; car_other, car and others) was calculated separately for weekdays and holidays in 2019 and 2020.

\subsubsection{Percentage Increase/Decrease in the Number of Visits to each Green Space and Distance Traveled}

The number of visits for each large green space was divided into 2019 and 2020. We also calculated the percentage increase or decrease based on the number of visits in 2019 and 2020 for each green space. Moreover, we calculated the median access distance of visitors to each green space and examined the relationship between the rate of increase/decrease, the number of visits, and the distance traveled.

\subsection{Results and Discussion}

\subsubsection{General Change of Activity Pattern}

To describe the overall pattern of movement change, as a pre-analysis, we visualized the movement of people in Kanazawa on holidays in 2019 and 2020 from the collected GPS data (Fig. 16.1 and Fig. 16.2). Many people were seen visiting Kanazawa Station and Kenroku-en Garden area in 2019 (Fig. 16.1), but few people were seen in 2020 (Fig. 16.2).

\subsubsection{Average Number of Outings and Total Time Spent out of the House per Day}

Comparing 2019 and 2020, the average number of times people go out on weekdays and holidays decreased (Fig. 16.3). Similarly, comparing 2019 and 2020, the average total time spent out of the house decreased on both weekdays and holidays (Fig. 16.4). From these results, there was a tendency to avoid going out at all and for long periods of time in 2020 . 


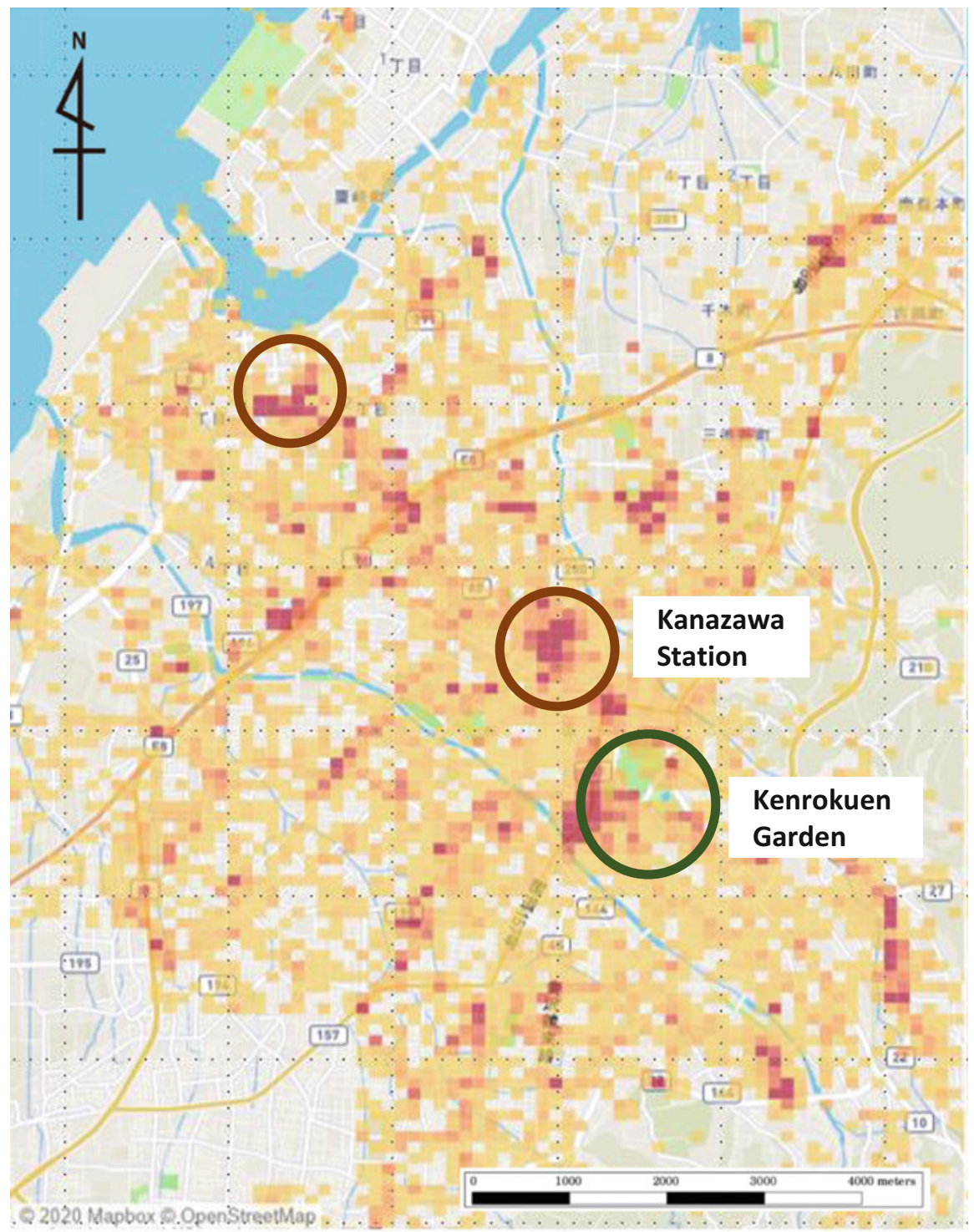

Fig. 16.1 Movement of people on holidays in 2019. The darker the color, the more people were concentrated in the area 


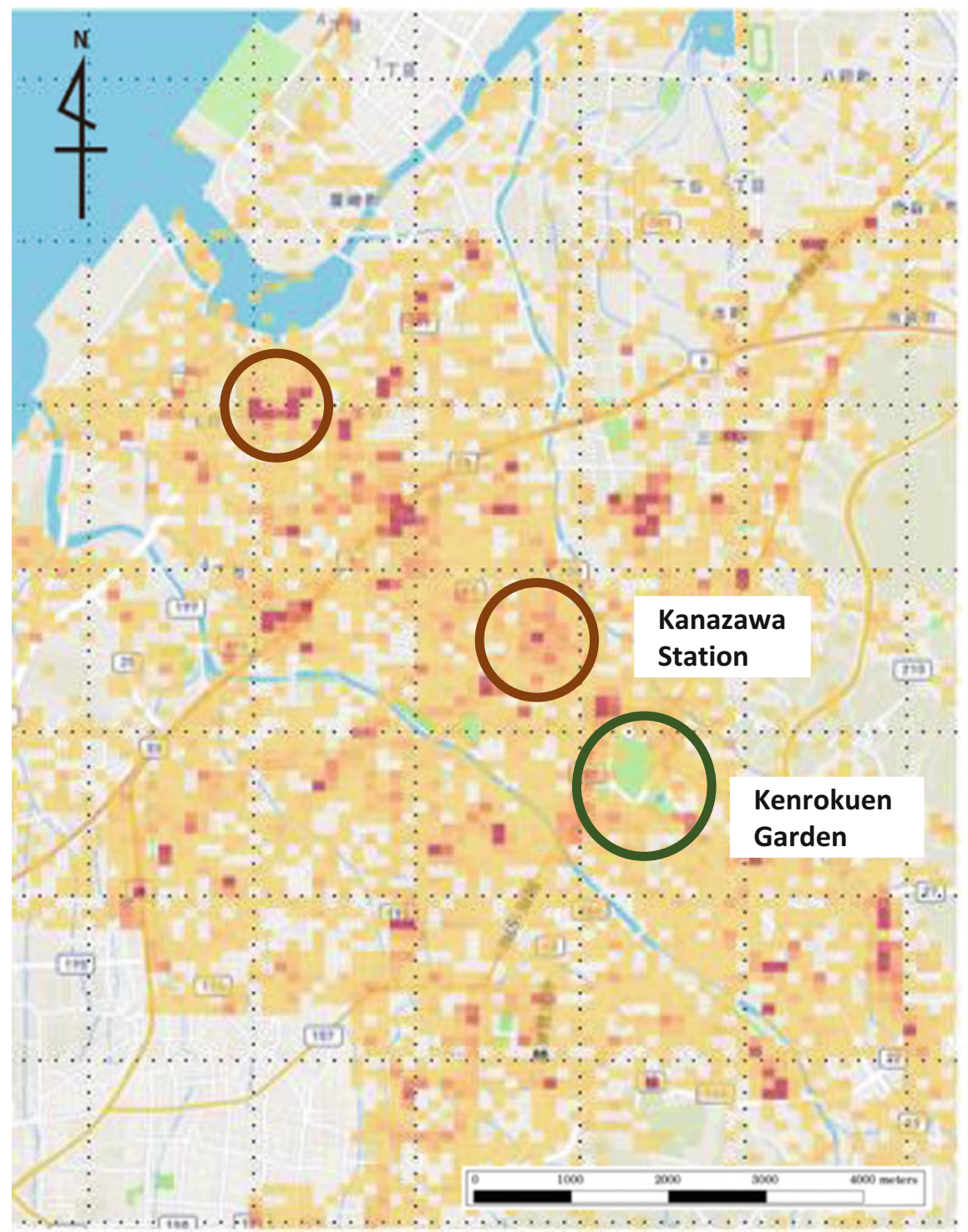

Fig. 16.2 Movement of people on holidays in 2020. The darker the color, the more people were concentrated in the area 


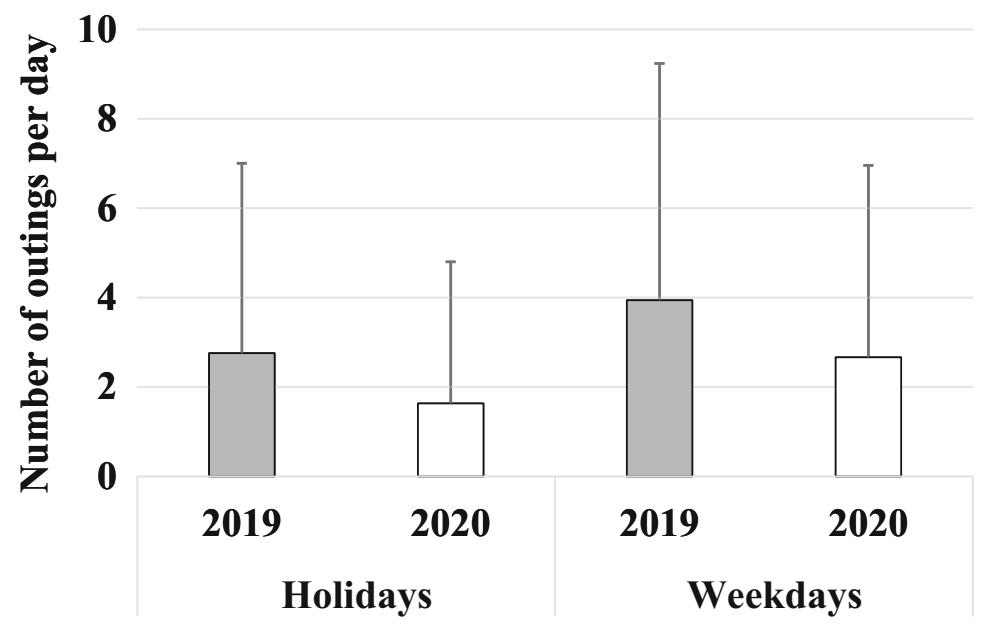

Fig. 16.3 Number of outings per day (mean \pm S.D.)

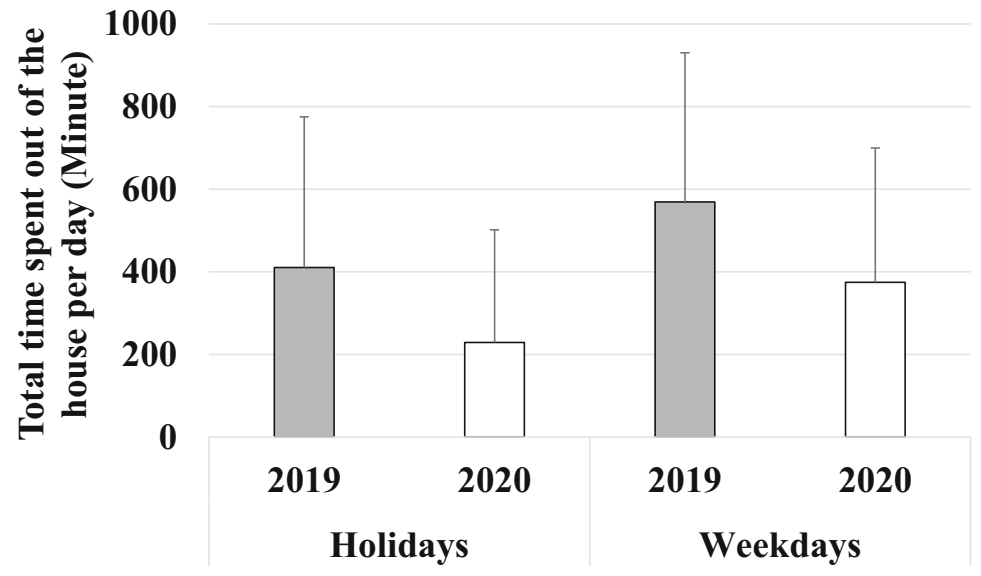

Fig. 16.4 Total time spent out of the house per day (mean \pm S.D.)

\subsubsection{Maximum Distance Traveled per Day}

The most common distance traveled in both 2019 and 2020 was between 0 and $1000 \mathrm{~m}$. In 2020, fewer people traveled more than $1000 \mathrm{~m}$ than in 2019 . Furthermore, there were few trips of more than $4000 \mathrm{~m}$ during holidays in 2020 (Fig. 16.5). From these results, there was a tendency to avoid going out for long distances in 2020 . 


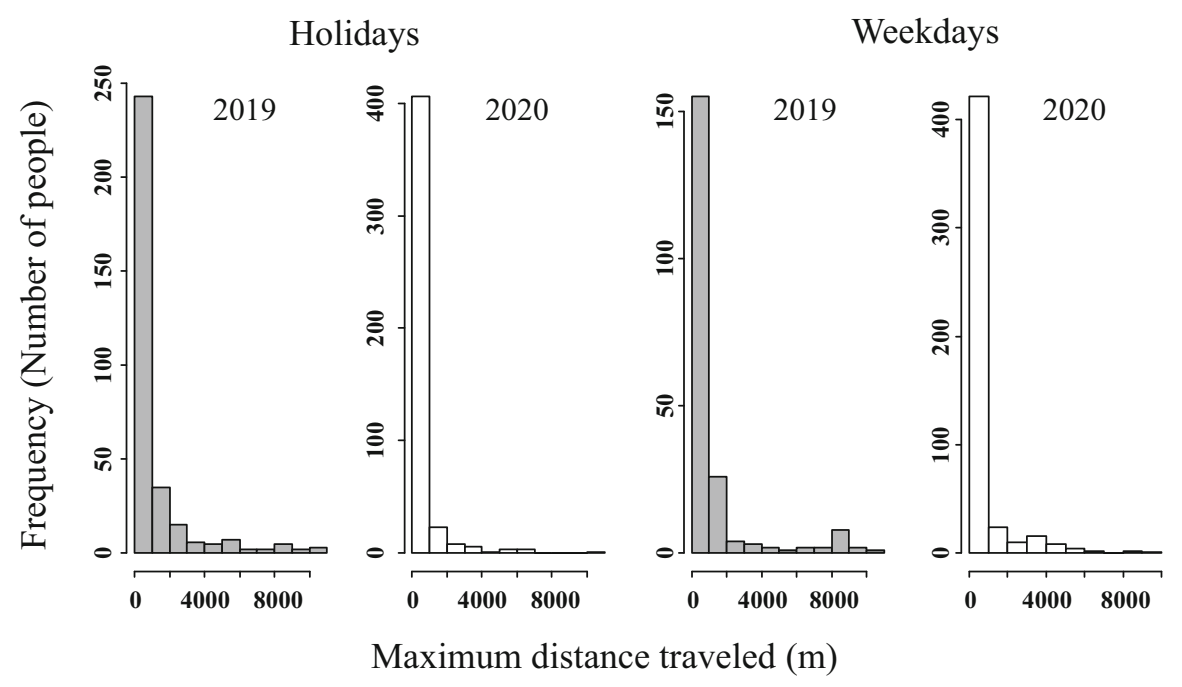

Fig. 16.5 Maximum distance traveled in a day

\subsubsection{Number of Outings by Means of Transportation}

The percentage of outings by car and other means of transportation (other than walking and bicycling) was the largest in both 2019 and 2020. 2020 saw an increase in the percentage of outings by walking and a relative decrease in the percentage of outings by bicycling and car and the others (Fig. 16.6). In 2020 compared to 2019 , the percentage of outings by walking increased on holidays, with a change of $118.7 \%$ (Fig. 16.6).

\subsubsection{Number of Visits by Destination}

The percentage of visits by destination for green areas and commercial areas did not change significantly between 2019 and 2020 (Fig. 16.7). The change in the number of visits by destination in 2020 compared to 2019 showed that the number of visits decreased for all destinations in 2020, but the percentage decrease for green areas was smaller (Fig. 16.7), with a slight increase of $100.06 \%$ during the consecutive holidays in May. 


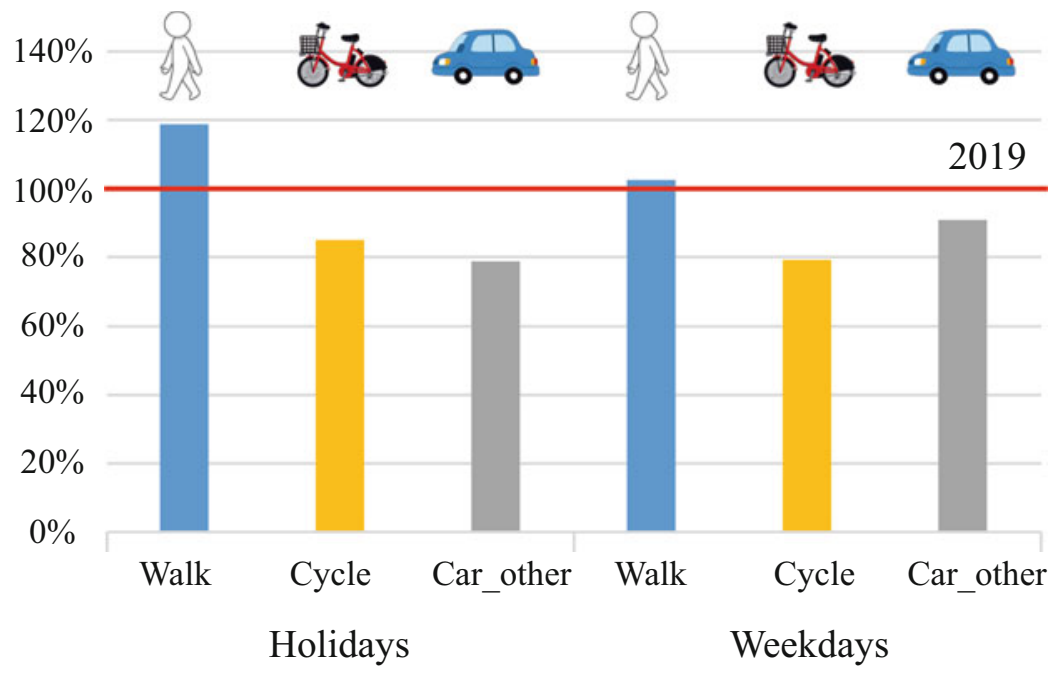

Fig. 16.6 Percentage change by means of travel in 2020 compared to 2019

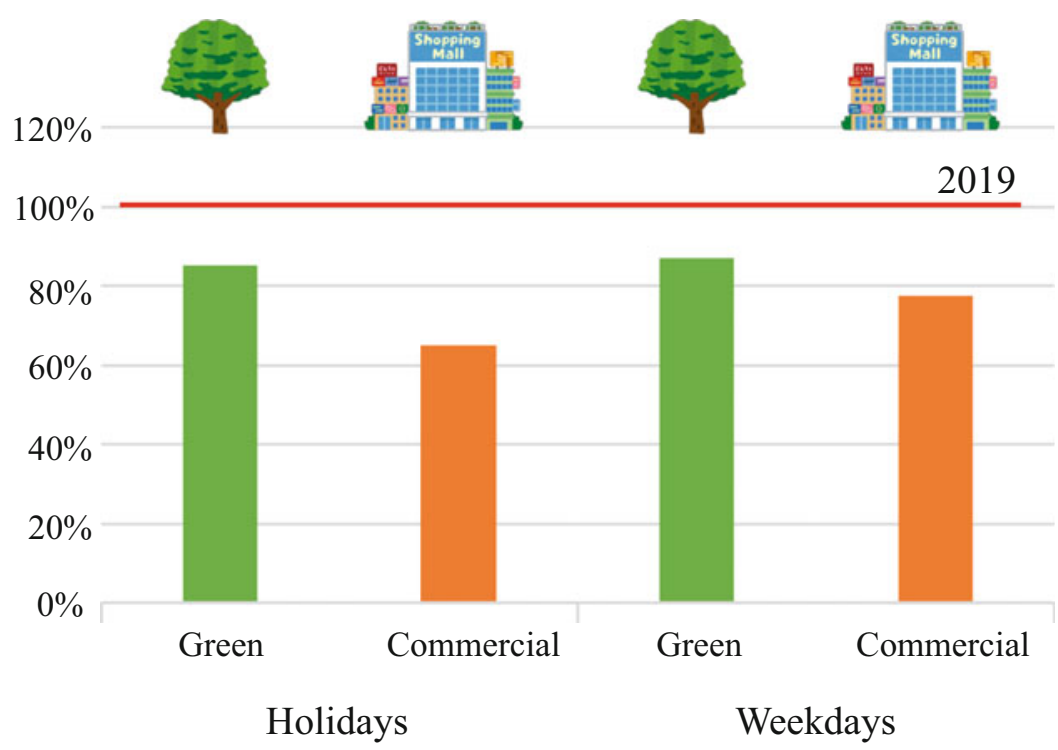

Fig. 16.7 Percentage change by destination in 2020 compared to 2019 


\subsubsection{Percentage Increase/Decrease in the Number of Visits to each Green Space and Distance Traveled}

While the number of visits to large-scale green spaces in central Kanazawa (e.g., Kanazawa Castle Park, Ishikawa Shiko Memorial Park), which had many visitors from far away and were used more frequently in 2019, decreased significantly to half or less in 2020, the percentage of visitors from short distances within $1000 \mathrm{~m}$ increased in 2020 (Fig. 16.8). In Fig. 16.8, the horizontal axis is the percentage change in the number of visits at a given green space in 2020 compared to 2019. The median of travel distances in 2019 and 2020 for a given green space are plotted vertically at the corresponding percent change in the number of visits. The vertical axis is the access distance from the user's home, so a particular green space is plotted at the median distance in 2019 and 2020, respectively. Figure 16.8 shows that (1) compared to 2019, the distance visited is generally shorter in 2020 (2020 bubbles located below 2019 bubbles); (2) green spaces with a large increase in the number of visitors in 2020 (green spaces plotted on the right side of the graph) have a visiting distance of around $1000 \mathrm{~m}$, which means that they are often visited by people from nearby areas. The results indicate that while the number of visits to green spaces and parks in the city center decreased, the number of visits to nearby parks and green spaces adjacent to residential areas increased. The results have implications for the importance of green spaces in and near residential areas during the periods of lifestyle restrictions.

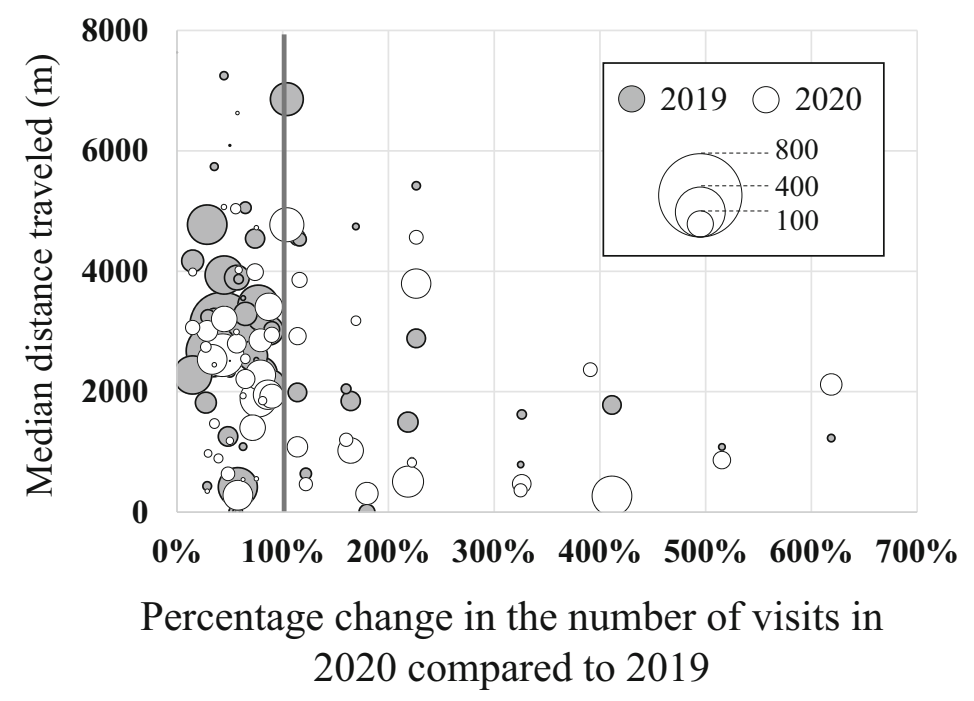

Fig. 16.8 Relationship between the rate of increase/decrease in the number of visits to each green space in Kanazawa City in 2020 compared to 2019 and the average distance traveled from home. Note that a bubble size indicates the number of visits 


\subsubsection{Green Space Planning in Kanazawa City in Relation to the Research Hypothesis}

The results show that during the pandemic, people avoided going out at all, including visits to large green spaces in city center, popular destination in 2019, to avoid crowding and unnecessary contact with other people. However, Fig. 16.8 shows that visits within $1000 \mathrm{~m}$ of home increased under the COVID-19 pandemic, and visits to green spaces around residential areas within a short distance from home increased in particular. Therefore, we believe that nearby green spaces within a $1000 \mathrm{~m}$ radius provided people with opportunities to use them for health maintenance and refreshment, supporting the research hypothesis. Short distances to green areas from the dwelling are associated with less stress and a lower likelihood of obesity (Nielsen and Hansen 2007). Along with facilitating social cohesion, stress reduction is a strong pathway to health (De Vries et al. 2013). Also, Soga et al. (2021) found that the frequency of green space use and the existence of green window views from within the home were positively associated with five measures of mental health outcomes. Although Lu et al. (2020) found that in Tokyo during the pandemic people preferred large parks close to city center, this may be due to the Instagram data bias, where visual beauty and famous locations are favored over a local park near residential areas.

Our analysis also revealed that even if there is a green space within 1000 from home, many people do not use it. Although the parks closest to home are considered to be those that are close to daily life and can be used easily, they are not always the most frequently used (Shimomura et al. 1995). Also, Kaczynski et al. (2014) showed that distance to the closest park is not an important factor in park use, but diverse park facilities are associated with park use and physical activity. More broadly, it is generally believed that people's nature experiences are determined by "opportunity" and "orientation" (emotional affinity with nature) (Soga and Gaston 2016), and recent studies in particular have shown that the latter is actually more influential (Lin et al. 2014). In other words, these studies suggest that when planning green spaces in a city, it is important not only to consider park proximity but also to place green spaces including parks in a way that matches the needs of the users. Organizing activities and events, policies, and education to increase people's nature orientation is also important for encouraging people's use of and visit to green spaces.

\subsection{Conclusions}

The results of the analysis in this study showed that the declaration of a state of emergency under the COVID-19 pandemic in Japan in April-May 2020 changed the outing behavior of Kanazawa citizens, and there was a strong tendency for them to avoid going out, with a decrease in the number, time, and distance of outings. On the other hand, while citizens refrained from going out, the rate of 
decrease in the number of visits to green spaces was small, and the number of walks increased slightly from 2019. The number of visits to green spaces near one's home increased slightly compared to 2019, while there was a tendency to avoid using green spaces in city center. These results suggest that those who had green spaces around their homes were able to use them for maintaining their health, refreshment, and other purposes during the COVID-19 pandemic, according to the big data. On the other hand, those who did not have green spaces around their homes went out less frequently but did not show a trend of increasing the rate of staying at home.

Urban parks and green spaces are green infrastructure that provides a variety of benefits to urban residents, and by utilizing the functions that nature provides, they can also offer solutions to societal challenges in cities (i.e., nature-based solutions). Historically, urban parks were one of the urban facilities developed in the eighteenth and nineteenth centuries for the purpose of ensuring public health and reducing environmental pollution (Chadwick 1966). In recent years, it has been reported that green spaces have various functions such as disaster prevention (e.g., shelter and refuge in case of disasters), microclimate mitigation, formation of an aesthetically pleasing landscape, branding of the area, increase in land prices in the surrounding area, habitats for local organisms, and places for local community activities. However, the amount of green space around residential areas differs greatly among cities around the world, and the more affluent districts tend to have more developed green space. On the other hand, in the Sustainable Development Goals (SDGs) agreed upon by the United Nations to be achieved by 2030, Goal 11 "Make cities and human settlements inclusive, safe, resilient and sustainable" has a target 11.7: "By 2030, provide universal access to safe, inclusive and accessible, green and public spaces, in particular for women and children, older persons and persons with disabilities." This study, conducted under the COVID-19 pandemic, reiterates the need for green infrastructure that is closely related to people's lives, such as urban green spaces, and shows the importance of creating a society where all urban residents, regardless of wealth, can enjoy the benefits of green spaces through strategic urban planning.

\section{References}

Bratman GN, Anderson CB, Berman MG et al (2019) Nature and mental health: an ecosystem service perspective. Sci Adv 5:903-927

Chadwick GF (1966) The park and the town; public landscape in the 19th and 20th centuries. F.A. Praeger, New York

De Vries S, van Dillen SME, Groenewegen PP, Spreeuwenberg P (2013) Streetscape greenery and health: stress, social cohesion and physical activity as mediators. Soc Sci Med 94:26-33. https:/ /doi.org/10.1016/j.socscimed.2013.06.030

Fong KC, Hart JE, James P (2018) A review of epidemiologic studies on greenness and health: updated literature through 2017. Curr Environ Heal reports 5:77-87

Hartig T, Mitchell R, de Vries S, Frumkin H (2014) Nature and health. Annu Rev Public Health 35:207-228. https://doi.org/10.1146/annurev-publhealth-032013-182443 
Ishikawa Prefecture (2020) Circumstances of infected patients. https://www.pref.ishikawa.lg.jp/ kansen/coronakennai2002.html. Accessed 16 Jan 2021

Kaczynski AT, Besenyi GM, Stanis SWA et al (2014) Are park proximity and park features related to park use and park-based physical activity among adults? Variations by multiple socio-demographic characteristics. Int J Behav Nutr Phys Act 11:114. https://doi.org/10.1186/ s12966-014-0146-4

Kanazawa City (n.d.) Kanazawa City Types of Urban Parks https://www4.city.kanazawa.lg.jp/ 29004/park/syurui.html. Accessed 16 Mar 2021

Keeler BL, Hamel P, McPhearson T et al (2019) Social-ecological and technological factors moderate the value of urban nature. Nat Sustain 2:29-38

Kondo M, Fluehr J, McKeon T, Branas C (2018) Urban green space and its impact on human health. Int J Environ Res Public Health 15:445. https://doi.org/10.3390/ijerph15030445

Lesser IA, Nienhuis CP (2020) The impact of COVID-19 on physical activity behavior and Well-being of Canadians. Int J Environ Res Public Health 17:3899. https://doi.org/10.3390/ ijerph17113899

Lin BB, Fuller RA, Bush R et al (2014) Opportunity or orientation? Who uses urban parks and why. PLoS One 9:87422. https://doi.org/10.1371/journal.pone.0087422

Lu Y, Zhao J, Wu X, Lo SM (2020) Escaping to nature in pandemic: a natural experiment of COVID-19 in Asian cities. doi:https://doi.org/10.31235/OSF.IO/RQ8SN

NHK Emergency declaration-1st situation (n.d.). https://www3.nhk.or.jp/news/special/ coronavirus/emergency/. Accessed 22 Feb 2021

Nielsen TS, Hansen KB (2007) Do green areas affect health? Results from a Danish survey on the use of green areas and health indicators. Heal Place 13:839-850. https://doi.org/10.1016/ j.healthplace.2007.02.001

NIKKEI (The Japan Economic Daily) (2020) In Europe and the United States, restrictions on private rights, penalties for going out, and enforcement differ from Japan. https:// www.nikkei.com/article/DGXMZO57774880X00C20A4EA1000/. Accessed 22 Feb 2021

Shimomura Y, Masuda N, Abe D et al (1995) Study on Resident's behavior of Block Park in neighborhood. J Japanese Inst Landsc Archit 58:217-220. https://doi.org/10.5632/jila.58.5_217

Soga M, Gaston KJ (2016) Extinction of experience: the loss of human-nature interactions. Front Ecol Environ 14:94-101

Soga M, Evans MJ, Tsuchiya K, Fukano Y (2021) A room with a green view: the importance of nearby nature for mental health during the COVID-19 pandemic. Ecol Appl 31:e2248. https:// doi.org/10.1002/eap.2248

Venter ZS, Barton DN, Gundersen V et al (2020) Urban nature in a time of crisis: recreational use of green space increases during the COVID-19 outbreak in Oslo, Norway. Environ Res Lett 15:104075. https://doi.org/10.1088/1748-9326/abb396

Zhou X, Parves Rana M (2012) Social benefits of urban green space. Mgmt Environ Qual Int J 23:173-189. https://doi.org/10.1108/14777831211204921

Open Access This chapter is licensed under the terms of the Creative Commons Attribution 4.0 International License (http://creativecommons.org/licenses/by/4.0/), which permits use, sharing, adaptation, distribution and reproduction in any medium or format, as long as you give appropriate credit to the original author(s) and the source, provide a link to the Creative Commons license and indicate if changes were made.

The images or other third party material in this chapter are included in the chapter's Creative Commons license, unless indicated otherwise in a credit line to the material. If material is not included in the chapter's Creative Commons license and your intended use is not permitted by statutory regulation or exceeds the permitted use, you will need to obtain permission directly from the copyright holder. 